\title{
TREATMENT OF CHRONIC LOW BACK PAIN
} INCORPORATING ACTIVE PATIENT PARTICIPATION AND CHIROPRACTIC: A RETROSPECTIVE CASE REPORT

\author{
LARRY LEGIER, DC ${ }^{a}$
}

${ }^{a}$ Private practice, Rochester, $M N$.

Submit requests for reprints to: Dr. Larry Legier, 1827 S. Broadway Ave., Rochester, MN 55904.

Paper submitted December 31, 2004.

Sources of support: No funds were received for the preparation of this manuscript.

\begin{abstract}
Objective: To present a retrospective case report about a patient who suffered from chronic lower back pain for sixteen years, finding little relief from numerous medical and traditional chiropractic interventions, until active patient participation was incorporated in the chiropractic treatment process.
\end{abstract}

Clinical Features: A 43-year-old female experienced severe right lumbar, right sacrum, and right acetabular pain and muscle spasms occurring after playing a vigorous tennis match 16 years earlier. Pain intensity was rated as 8 out of 10 on a variable analog scale. Prior treatments included prolonged bed rest, cortisone injection, chiropractic manipulation, stretching, acupuncture, physical therapy, and other rehabilitation interventions. By the time of presentation she also experienced right arm and right upper back pain. A lumbar MRI scan showed an L4/5 disc bulge. Patrick's, Yeoman's and Kemp's tests were positive on her right side. She had an asymmetrical gait pattern with a right hip hike, lateral shift and rotation of the pelvis. Weakness of the left gluteus maximus, gluteus medius, and right erector spinae muscles was present. Motion palpation revealed several fixations. There was tenderness to palpation of the right psoas muscle and a trigger point in the right illiacus muscle.

Intervention and Outcome: Home-based rehabilitation including low-tech muscle-specific patient controlled $d y$ namic spinal stabilization exercises, cardiovascular training and various stretching techniques was incorporated with chiropractic manipulation. Significant improvement was noted within a 40 week treatment course.

Conclusion: Incorporation of active patient participation seemed to be a significant factor in the resolution of the patient's low back pain. Active patient participation improved the quality of life for this patient. (J Chiropr Med 2005:4:200-205)

Key Indexing Terms: Low Back Pain; Chiropractic; Rehabilitation; Exercise Therapy

\section{INTRODUCTION}

Often patients who have chronic low back pain (LBP) over an extended period of years, with the absence of classic orthopedic/neurological objective findings, are viewed as malingers, psychologically imbalanced, or hypochondriac. ${ }^{1}$ The purpose of this retrospective case report is to demonstrate the effectiveness of changing treatment methodologies from passive to active care in a chronic LBP patient. Secondly, there is a void in the literature as to the relationship or causality regarding the value, techniques or role of patient directed /active patient participation chiropractic treatment as a preferred treatment approach.

For the purpose of this paper, passive care refers to treatment designed, administered, and directed solely by the practitioner. Active treatment refers to the incorporation of patient subjective data, patient participation in exercises, and chiropractic care in a holistic treatment modality. Grounded in educational retrospective single case report methodology, ${ }^{2}$ this paper seeks to challenge preconceived assumptions within the discipline by offering a debate as to the value of passive medical/chiropractic care and active patient participation in relieving pain and physical limitations.

\section{CASE REPORT}

\section{Patient History}

The patient was a 43-year-old female computer programmer who experienced severe right lumbar, 
right sacrum, and right acetabular pain. The onset of pain occurred 1 day after playing a vigorous tennis match at the age 27. Prior to the tennis match in question, the patient was an extremely active individual with no limitations on her activities of daily living. She grew up on an apple orchard and did chores such as baling hay, picking apples, and carrying the filled 40 pound sacks of apples. Her work days were often 16 hours long. For recreation she enjoyed skiing, hiking, biking, tennis, and acoustic guitar.

Initially her chief complaint was right sacral pain accompanied by muscle spasms in the low back and pelvic region. The muscle spasms lasted for a period of 6 months. Pain intensity was rated as 8 out of 10 on a pain scale. The initial treatment prescribed for her by her medical doctor was a full summer of bed rest. The treatment yielded minimal subjective improvement. Physical inactivity complicated the spinal/muscle dysfunction as she became "out of shape." At the end of the summer, an injection of cortisone was administered at the sacrum. The cortisone had no impact on the condition and the subjective complaints and spasms persisted. One year, after the injury, at age 28 , the patient began to swim and participate in some increased physical activity. However, she was still substantially affected by her back pain. Pain intensity was rated as a 6 on a pain scale. Three years after her injury, now at age 30 , the subject had her initial contact with a doctor of chiropractic whose treatment consisted of adjustments and stretching. The chiropractic treatments helped some and marginal improvements were observed. Over the next 3 years, the patient integrated more walking into her lifestyle in a personal attempt to recondition her muscle tone. However, she soon developed an abnormal gait pattern that was noted by her friends and co-workers.

Over the following 13 years the patient was under intermittent passive chiropractic care experiencing occasional exacerbations and remission of symptoms. During this period she never returned to her pre-injury status. Pain still dramatically affected her activities of daily living. Over the course of 13 years she also sought out treatment which utilized acupuncture, physical therapy, physical medicine, and rehabilitation interventions at a well known Midwestern medical facility. At age 41 , the patient's lower back pain dramatically increased in intensity. In addition to the back pain, the patient began to experience right arm and right upper back pain, the pain being so severe she described it as literally, "...taking her breath away." Passive chiropractic and physical therapy were of little help. Acupuncture treatment provided minimal improvement in the patient's shoulder and arm pain for short durations of time. She reported that she was constantly stretching and exercising on her own to obtain relief. The patient noted that there was, "...something out of balance on the right side of my body."

The patient was referred to our office by a massage therapist because the patient sought some additional relief and was open to other treatment modalities. Table 1 provides a summary of patient's passive treatment history.

\section{Examination}

Physical examination revealed a very fit, athletic, 43-year-old, 61 in, 104 lb woman. X-ray examination revealed minimal joint or degenerative disc changes. The only significant finding on $\mathrm{x}$-ray was right L-5 spatulation with a pseudo joint at the right iliac crest. An MRI of the lumbar spine indicated an L-4 bulge and L-5 was negative. Orthopedic and neurological examinations were unremarkable. Reflexes were normal, plantar flexion was bilaterally strong, and there were no bowel, bladder, or urinary tract signs. Straight leg raise for nerve tension signs or disc lesions was negative. The Patrick's

TABLE 1

PASSIVE TREATMENT SUMMARY

\begin{tabular}{|c|c|c|}
\hline PATIENT AGE & PRESCRIBED TREATMENT & RESULTS \\
\hline 27 & FOUR MONTHS BED REST. & $\begin{array}{l}\text { MINIMAL SUBJECTIVE IMPROVEMENT AND FEELING “OUT } \\
\text { OF SHAPE”. }\end{array}$ \\
\hline 28 & CORTISONE INJECTION. SWIMMING AND WALKING. & $\begin{array}{l}\text { NO IMPROVEMENT. BETTER OVERALL PHYSICAL } \\
\text { CONDITIONING. }\end{array}$ \\
\hline 30 & INITIAL CHIROPRACTIC TREATMENTS. & MILD IMPROVEMENT. \\
\hline 33 & $\begin{array}{l}\text { ACUPUNCTURE, PHYSICAL THERAPY, PHYSICAL } \\
\text { MEDICINE, AND REHABILITATION CLINIC. }\end{array}$ & MILD IMPROVEMENT. \\
\hline 41 & CHIROPRACTIC, ACUPUNCTURE, PHYSICAL THERAPY. & $\begin{array}{l}\text { EXACERBATION OF THE LUMBAR WITH ADDITIONAL } \\
\text { UPPER BACK AND ARM PAIN. NO RELIEF. }\end{array}$ \\
\hline
\end{tabular}


FABERE test was mildly positive on the right, indicative of acetabular irritation. Right Yeoman's hip extension was positive on the right for sacroiliac or lumbar/sacral irritation and Kemp's lumbar lateral flexion was positive for lower lumbar facet irritation.

Findings from functional examinations were subtle with the exception of an asymmetrical gait pattern. A right iliac hip hike along with lateral shift and rotation of the pelvis were noted as the patient walked. It is hypothesized that this hip hike and lateral shift with rotation of pelvis most likely resulted in the upper back, shoulder, and arm complex. The exam also revealed relative weakness of the left gluteus maximus, gluteus medius, and right erector spinae muscles. Motion palpation revealed a right L-5 lateral flexion fixation, right lower sacroiliac fixation, mid-thoracic right lateral flexion fixation and left lower cervical lateral bending fixation. There was right psoas tenderness to palpation and a marked trigger point at right illiacus muscle. Careful assessment is imperative as the illiacus muscle provides hip flexion and stabilization and can give patient symptoms of mild appendicitis with accompanying abdominal pain. ${ }^{3}$

From the examination it did not appear that this patient met the diagnostic criteria for a classic sciatica or disc herniation. In addition, the patient did not seem to have the condition known as "meralgia paresthetica," a lateral thigh paresthesia from the lateral femoral cutaneous nerve. Initial working diagnosis was sacroiliac dysfunction, lumbar facet irritation complicated by L-5 spatulation/enlargement of the right L-5 transverse process, resulting in a pseudo joint at iliac crest. Spatulation affects the biomechanical dynamics of the pelvis with one side having restricted movement via the pseudo joint.

\section{Treatment}

Since many passive therapies were tried previously, muscle-specific, dynamic spinal stabilization exercises (active treatment) in conjunction with specific chiropractic manipulative therapy (passive treatment) were used in an attempt to alleviate this chronic problem. Initial treatment consisted of chiropractic adjustments and specific spinal stabilization exercises as active treatment. Each exercise prescribed was first demonstrated for proper technique then monitored for proper patient demonstration and form. The patient was not allowed to advance to a new exercise unless she was able to demonstrate proper understanding of form and technique since, "simple educational approaches with or without written information alone are not effective in managing lumbar pain patients." ${ }^{4}$

The first exercise was the pelvic tilt with bridge to facilitate the lumbopelvic and gluteus muscles. Adding a rubber belt around the knees with resisted abduction facilitated gluteus medius, gluteus maximus, and deep lumbar pelvic muscle strengthening to develop the lateral muscular pelvic brace. ${ }^{5}$ Muscle control of the lumbodorsal muscles allows greater resistance to bending and loading stresses. The role of the lumbodorsal fascia is comparable to the anchoring devices on a circus tent. The anchoring devices pull on the sides of the tent, stabilizing the whole tent around the center pole. Similarly, the lumbosacral fascia stabilizes the trunk with balanced, evenly distributed tension. To enhance and strengthen the role of the lumbodorsal fascia, exercises concentrated on trunk strength, mobility, balance and coordination as well as aerobic conditioning $^{5}$ as muscle groups are exercised to create a 'dynamic corset' that can maintain the neutral position. ${ }^{6}$ It was anticipated that there would be a decrease in pain since muscle strength and density appear to be correlated with lumbar pain. ${ }^{7}$

At the next visit the patient purchased a $65 \mathrm{~cm}$ Swiss Ball to aid in her rehabilitation program. The patient was taught the "fabulous five" exercises developed by Ierna. ${ }^{8}$ These exercises include: 1) Pelvic tilt with bridge (Lumbo pelvic muscles, gluteus maximus); 2) Abdominal crunches (abdominal muscles); 3) Prone extension exercises with $20 \%$ more repetitions than abdominal crunches (extensors); 4) Side-ups right and left (quadratus lumborum); 5) Wall squats (gluteus, hamstrings, and quadriceps).

The patient was instructed to do home "post isometric relaxation" stretching techniques to help stretch the weak, tight gluteus minimus, gluteus maximus, piriformis, psoas, tensor facia lata, and quadratus lumborum muscles. After 6 weeks, some upper body stabilization exercises were added, specifically using a 10 inch kickball up against the wall for the deep neck flexors. The patient nods the head in 'yes' movement along with some chin tuck in an effort to facilitate the deep neck flexors in order to inhibit suboccipital muscles and reduce anterior translation 
of the head. For the exercise, the weight of the head should be over the shoulders and arch of feet. Additionally, middle and lower trapezius exercises were incorporated using theraband tubing, a rowing machine and a home Schwinn Airdyne as an upper body ergometer. The patient was instructed to pull the lower angles of the scapulae together.

Two and a half months into the program the author suggested that the patient purchase Janda sandals. These sandals have a half ball on the arch demanding greater proprioception skills during exercise that helps with the speed of activation of the gluteal muscles. The patient also purchased a rocker board to develop multifidi muscle intersegmental spinal stabilization. The addition of the rocker board and sandals dramatically helped with the abnormal gait patterns and the patient reported that she could walk smoothly without the noticeable abnormal gait. Lattisimus dorsi pulls downs were added later to help stabilize the thoraco-lumbar junction and develop low back stability. Finally vastus medialis oblique exercises were added for knee stabilization.

The patient was compliant, motivated, and actively engaged. She was encouraged during the entire treatment process. Oftentimes she would exercise 3-5 hr per day. At one point she asked if 400 bridges a day were enough. She brought the rocker board, sandals, Swiss ball, and Theraband to her office. At noon she attended a Healthy Living Center to exercise, which she reported helped her both psychologically and physically with periods of long sitting.
At home she complied with her treatment exercises utilizing the Schwinn Airdyne and Nordic Track.

After 3 visits she noted that she was seeing some improvement. At 2 months she stated she was, "So much better it is fantastic!" At three months she reported 'less pain, it is the first time I am able to snow ski in 3 years.' At 5 months she reported that the 'sacroiliac joint and the pelvis are getting stronger.' At the tenth month she reported she was ' $80 \%$ better overall,' with much more strength, smoother gait and able to increase activities of daily living. There were 35 chiropractic visits over the course of 10 months. A summary of the active treatment process, prescribed treatment and rationale is provided in Table 2.

\section{DISCUSSION}

The minimal initial relief from passive treatment noted by the patient is consistent with findings in the literature. There appears to be substance to Walling's "rule of seven" in which the average chiropractic patient has functional recovery after 7 days, symptoms resolve after 7 weeks, and within 7 months 7 out of 10 patients will experience a reoccurrence of pain. ${ }^{9}$ Prolonged rest is no longer advocated and the benefits of exercise are becoming increasingly clear. ${ }^{10}$ Cortisone injections had no impact on the condition and the subjective complaints of spasms persisted and epidural analgesia initially provided relief but were found insignificant at one year. ${ }^{11}$ Causes of symptoms of LBP remain un-

TABLE 2

ACTIVE TREATMENT SUMMARY

\begin{tabular}{|c|c|c|}
\hline $\begin{array}{c}\text { TIME } \\
(\text { WEEKS) }\end{array}$ & PRESCRIBED TREATMENT & RATIONALE \\
\hline 1 & PELVIC TILT WITH BRIDGE. & $\begin{array}{l}\text { FACILITATE STRENGTHENING LUMBOPELVIC AND } \\
\text { GLUEAL MUSCLES. }\end{array}$ \\
\hline 2 & $65 \mathrm{CM}$. SWISS BALL. & ASSIST IN FLEXIBILITY EXERCISES. \\
\hline 3 & "FABULOUS FIVE" EXERCISES. & $\begin{array}{l}\text { FACILITATE STRENGTHENING OF LUMBOPELVIC, } \\
\text { LUMBO/DORSAL, AND GLUTEAL MUSCLES. }\end{array}$ \\
\hline 4 & POST ISOMETRIC RELAXATION, "CONTRACT AND RELAX”. & RELAX, LENGTHEN TIGHT MUSCLES. \\
\hline 6 & $\begin{array}{l}\text { UPPER BODY STABILIZATION. SCHWINN AIRDYNE, BAND } \\
\text { TUBING, AND ROWING MACHINE. }\end{array}$ & $\begin{array}{l}\text { FACILITATE/STRENGTHEN MIDDLE AND LOWER } \\
\text { TRAPEZIUS MUSCLES. AID IN SCAPULA-THORACIC } \\
\text { RHYTHM. }\end{array}$ \\
\hline 10 & JANDA SANDALS. & JOINT PROPRIOCEPTION AND ACTIVATION OF MUSCLES. \\
\hline 11 & ROCKER BOARD. & JOINT PROPRIOCEPTION AND ACTIVATION OF MUSCLES. \\
\hline 16 & LATTISIMUS DORSI PULL DOWNS. & SPINAL STABILIZATION. \\
\hline 20 & VASTUS MEDIALLIS KNEE EXERCISES. & STABILIZE KNEES. \\
\hline $21-39$ & $\begin{array}{l}\text { CONTINUE ALL “LOW TECH” REHABILITATION PROGRAMS. } \\
\text { ADD DAILY LUNCH WORK OUTS AT HEALTHY LIVING } \\
\text { CENTER AND ONE HOUR/THREE DAYS A WEEK SWIM } \\
\text { PROGRAM. }\end{array}$ & $\begin{array}{l}\text { SPINE STABILIZATION. AEROBIC CONDITIONING. } \\
\text { REDUCE PSYCHOLOGICAL STRESS. }\end{array}$ \\
\hline 40 & DISCHARGED FROM TREATMENT. & PAIN RATED 2 OUT OF 10 ON VARIABLE ANALOG SCALE. \\
\hline
\end{tabular}


known despite full and appropriate use of modern imagining techniques. ${ }^{12,13}$ Finding of sacroiliac joint dysfunction is indicative of damage to ligaments or the low back. ${ }^{14-16}$ Research has indicated that most patients with lumbar pain do not have neurological problems but back pain usually results from injury related to the soft tissues. ${ }^{17}$

The patient and her doctor both noted positive objective and subjective improvements from the onset of the active patient rehabilitation program. Subjective improvements were first noted at the third visit and improvements continued over time and never really exhibited a plateau. Over the course of 10 months there were a couple of episodes of exacerbations, which were quieted within a day or a week.

Of key importance is for the patient to demonstrate understanding of the prescribed exercise prior to leaving the session. Active patient exercise techniques integrated into the treatment process not only benefited the patient's overall conditioning, but have proven to alleviate swelling and improve hydration of the surrounding soft tissue. ${ }^{18}$ Moreover, exercise is more effective for chronic LBP than treatment with medication. ${ }^{1,19}$ Regular graded exercise programs have demonstrated better assistance in recovery and preventing reoccurrence. ${ }^{5}$ Cardiovascular fitness programs similar to what was prescribed not only improve nutrition to all connective tissue, but offer additional advantages of weight control, muscle endurance, and higher endorphin levels which elevate the patients mood. ${ }^{20}$

It is therefore argued that this patient would never have achieved these accomplishments without her diligence and the incorporation of the active rehabilitation protocol. Previously she had little or no improvement with a multitude of interventions. It is clear that active participation by the patient is essential with these chronic pain/dysfunction syndromes. ${ }^{19,21-24}$ As a result, active care should be more utilized and further researched. Low tech rehabilitation equipment including elastic tubing, rocker boards, and a Swiss ball that are a minimal cost could equip a patient's home with a very functional low-tech rehabilitation center. ${ }^{25}$ A multitude of additional tissue specific exercises could be performed with this miniature home rehabilitation center. This has the potential for major economic impact since $85 \%$ of the money spent on the treatment of lumbar patients which is approximately $10 \%$ of all patients. ${ }^{26,27}$
There are some cautions and limitations of this paper. First, since this is a single case report, the very use of this methodology creates limitations and therefore generalization is cautioned. Further research and development of the literature incorporating these therapeutic modalities are warranted. Second, there is the risk of patients to become overly committed or "obsessed" with prescribed treatments when relief is experienced. Caution should therefore be taken prior to prescribing active treatment to patients who display obsessive compulsive traits ${ }^{1}$ or tendencies, as it could result in exacerbation of the problem. Recent studies have demonstrated a relationship between psychopathology and chronic LBP disability. However, psychopathology does not necessarily interfere with successful treatment outcomes and the patient's ability to return to work. ${ }^{28}$ Third, one study (although limited in scope) concluded that behavioral treatment had a small to moderate beneficial effect on pain, functional and behavioral outcomes in patients with chronic LBP. ${ }^{29}$ Finally, the current literature is limited as to empirical research being done in this area. For the field and chiropractic medicine to advance, this must be undertaken.

\section{CONCLUSION}

Incorporation of active patient participation seemed to be a significant factor in the resolution of the patient's LBP. Active patient participation improved the quality of life for this patient.

\section{REFERENCES}

1. American Psychiatric Association. Diagnostic and statistical manual of mental disorders. $4^{\text {th }}$ ed. Washington, DC: The Association; 1994.

2. Keating JC. Towards a philosophy of the science of chiropractic: a primer for clinicians. Stockton, CA: Stockton Foundation for Chiropractic Research; 1992. p. 199-222.

3. Rasch J, Burke R. Kinesiology and applied anatomy. $6^{\text {th }}$ ed. Philadelphia: Lea \& Febiger; 1978.

4. Watson P, Collett B. Chronic low back pain. BMJ 2003;327:107-8.

5. Liebenson C. Rehabilitation of the spine. Baltimore: Williams and Wilkins; 1996.

6. Saal JA, Saal JS. Nonoperative treatment of herniated lumbar intervertebral disc with radiculopathy-an outcome study. Spine 1989; $14: 431-7$.

7. Hultman G, Nordin N, Saraste H, et.al. Body composition, endurance, strength, cross sectional area, and density of erector spiny muscles in men with or without low back pain. J Spinal Disord 1993;6:1 14-23.

8. American Chiropractic Educational Services. Rehabilitation diploma program session three. Toronto: Canadian Memorial Chiropractic College; 1996.

9. Walling A. Management of chronic low back pain. Am Fam Physician. 2001;63:2277.

10. Mooney V, Leggert S. Back pain: which exercises can help, which can harm? Consultant 1996;36:2543-9.

11. Carter I. How effective are exercise and physical therapy for chronic low back pain? J Fam Pract 2002;5:209-10. 
12. Cooper R. Understanding paraspinal muscle dysfunction in low back pain: a way forward? Ann Rheum Dis 1993;52:413-5.

13. Bowden SD, Davis DO, Dina TS, et al. Abnormal magnetic resonance scans of lumbar spine in asymptomatic subjects. J Bone Joint Surg 1990;72:403.

14. Saly JM, Frame PS, Rapoza PA. Sacroiliac subluxation: a common, treatable cause of low back pain in pregnancy. Fam Pract Res J 1991; 11:149-59.

15. Schwartz RG, Sagedy N. Prolotherapy: a literature review and retrospective study. J Neurol Orthop Med Surg 1991;12:220-3.

16. Klein RG, Eek BC, DeLong WB, Mooney V. A randomized double-blind trial of dextrose-glycerinephenol injections for chronic, low back pain. J Spinal Disord 1993;6:23-33.

17. Spangfort EVV. The lumbar disc herniation. Acta Orthop Scand 1972; S142:1-45.

18. Scientific approach to the assessment and management of activityrelated spinal disorders. A monograph for clinicians. Report of the Quebec Task Force on Spinal Disorders. Spine 1987;12 (7Suppl):S1 S8.

19. Dolin SJ, Bacon RA, Drage M. Rehabilitation of chronic low back pain using continuous epidural analgesia. Disabil Rehabil 2002;20:151-7.
20. Nutter P. Aerobic exercise in treatment and prevention of low back pain. Occup Med 1988;3:137-45.

21. Shekelle P. Conservative exercises were effective for acute low-back pain after 5 years. ACP J Club 1995;123:33.

22. Lawerence V. Spinal manipulation for low back pain. A meta-analysis. ACP J Club 1993;118:9.

23. Samanta A, Beardsley J. Low back pain: which is the best way forward? BMJ 1999;318:1122-3.

24. Frazier LM. Facet joint injection did not relieve chronic low back pain. ACP J Club 1992;114:6.

25. Margo K. Diagnosis, treatment and prognosis in patients with low back pain. Am Fam Physician 1994;49:171-82.

26. Frymoyer JW, Cats-Baril WL. An overview of the incidences and cost of low back pain. Orthop Clin North Am 1991;22:263-71.

27. Volinn E, Turczyn KM, Loeser JD., Theories of back pain and health case utilization. Neurosurg Clin North Am 1991;2:739-48.

28. Gatchel RJ, Polatin PB, Mayer TG, Garcy PD. Psychopathology and the rehabilitation of patients with chronic low back pain disability. Arch Phys Med Rehabil 1994;75:666-70.

29. Allen R, Williams A. Behavioral treatment for chronic low back pain. Evid Based Ment Health 2001;4:55. 